\title{
Brief communication: Light-absorbing impurities can reduce the density of melting snow
}

\author{
O. Meinander ${ }^{1}$, A. Kontu ${ }^{2}$, A. Virkkula ${ }^{1}$, A. Arola ${ }^{3}$, L. Backman ${ }^{1}$, P. Dagsson-Waldhauserováa ${ }^{4,5}$, O. Järvinen ${ }^{6}$, \\ T. Manninen ${ }^{1}$, J. Svensson ${ }^{1}$, G. de Leeuw ${ }^{1,6}$, and M. Leppäranta ${ }^{6}$ \\ ${ }^{1}$ Finnish Meteorological Institute, Helsinki, Finland \\ ${ }^{2}$ Arctic Research Center, Finnish Meteorological Institute, Sodankylä, Finland \\ ${ }^{3}$ Kuopio Unit, Finnish Meteorological Institute, Kuopio, Finland \\ ${ }^{4}$ University of Iceland, Department of Physics, Reykjavik, Iceland \\ ${ }^{5}$ Agricultural University of Iceland, Faculty of Environment, Hvanneyri, Iceland \\ ${ }^{6}$ Department of Physics, University of Helsinki, Helsinki, Finland \\ Correspondence to: O. Meinander (outi.meinander@fmi.fi)
}

Received: 20 November 2013 - Published in The Cryosphere Discuss.: 10 January 2014

Revised: 10 April 2014 - Accepted: 14 April 2014 - Published: 26 May 2014

\begin{abstract}
Climatic effects of black carbon (BC) deposition on snow have been proposed to result from reduced snow albedo and increased melt due to light-absorbing particles. In this study, we hypothesize that BC may decrease the liquidwater retention capacity of melting snow, and present our first data, where both the snow density and elemental carbon content were measured. In our experiments, artificially added light-absorbing impurities decreased the density of seasonally melting natural snow. No relationship was found in case of natural non-melting snow. We also suggest three possible processes that might lead to lower snow density.
\end{abstract}

\section{Introduction}

For seasonal snow, snow melting is an important part of the natural annual hydrological cycle. It is forced by atmospheric sensible heat flux and solar radiation, where the albedo is a critical factor due to its large variability. Snow albedo depends primarily on the grain size, wetness, impurities in the near-surface snow layer, and directional distribution of the down-welling irradiance. Deposition of anthropogenic emissions to snow cover potentially causes albedo changes. In terms of its climate forcing, black carbon (also known as light-absorbing aerosol) has been hypothesized to be the second most important human emission, and only carbon dioxide is estimated to have a greater forcing (Bond et al., 2013).
The climatic effects of black carbon (BC) in snow are due to reduced snow albedo caused by absorption of solar radiation, and induced melt of darker snow, which again lowers the albedo via the albedo feedback mechanism (e.g. Warren and Wiscombe, 1980; Doherty et al., 2010).

Snow melt starts when snow temperature reaches the melting point. Then, if the heating continues, the volume of liquid water increases until the holding capacity or the saturation point of liquid water is reached. This capacity is $3-5 \%$ on a mass basis and depends on snow grain structure and packing (DeWalle and Rango, 2008). When the flow of melt water begins, the impurities may either be washed down through the snow with the flow, or remain in the snow. It has been shown that $\mathrm{BC}$ is less likely to be washed down through the snow with melt water (Conway et al., 1996; Doherty et al., 2013).

Hence, if we consider natural snow with anthropogenic $\mathrm{BC}$, we can assume this impurity to remain in the melting snowpack, not to be washed down, and to potentially cause changes in the snow properties and structure, as compared to clean snow. Therefore, we hypothesize that BC in snow might affect the liquid-water retention capacity of melting snow. To test this hypothesis, we use our data of cold and melting snow, where both the snow density and $\mathrm{BC}$ content were measured. 


\section{Materials}

All our snow density and BC data have been obtained for natural seasonally melting snow in Sodankylä $\left(67^{\circ} 25^{\prime} \mathrm{N}\right.$, $26^{\circ} 35^{\prime} \mathrm{E}$ ), Finland, north of the Arctic Circle. By natural snow we refer to a snow pack that has formed from snowfall (i.e. has not been produced by a snow cannon, and has not been affected by human activity, e.g. snow clearing). The data contain cases of cold and melting snow, both with and without experimentally added impurities (Table 1).

The cold snow samples were snow on a lake (17 March 2009), various sites around the Sodankylä area (13 and 19 March 2009 and 23-24 March 2010), and a fenced experimental field (6 and 10 April 2013). The melting snow data were from the experimental field only (17-18 April 2013 before and after rain).

The data originate from three campaigns: the Soot on Snow experiment in 2013 (SoS-2013); the Snow Reflectance Transition Experiment (SNORTEX 2008-2010, see Meinander et al., 2013 for more details); and the SnowRadiancecampaign (SR-2009). The SoS-2013 campaign was carried out at the Sodankylä airport to study the effects of deposition of impurities on surface reflectance, albedo and melt of seasonal snow. The experimental area was a large, flat, fenced open space, and the gravel ground was not covered with concrete or asphalt (Fig. 1). Different amounts of impurities were deposited to snow on different spots, each with diameter of $4 \mathrm{~m}$, and thereafter the spots were monitored until the snow had melted. The sites were left to develop naturally, introducing as little disturbance as possible. Here we used data from three experimental spots with chimney soot, one spot with Icelandic volcanic sand from Ólafur Arnalds (Agricultural University of Iceland) and Haraldur Olafsson (University of Iceland), and one reference spot.

The SnowRadiance (SR) was an ESA-funded project aiming at determining snow properties from optical satellite measurements. The BC samples were collected from the snow over ice on Lake Orajärvi. The lake is frequently used in the winter, e.g. for snowmobiling.

During the SoS-2013, the SNORTEX-2009, and the SR2009 campaigns, surface snow samples were collected for analysis of their elemental carbon (EC) and organic carbon (OC) concentrations using the filter-based thermal-optical method, described and used in, for example, Forsström et al. (2009). The EC is used as a proxy of BC, due to the measurement technique used. In the SNORTEX-2010 campaign, the sampling, filtering, and laboratory spectrometer analysis followed the procedures presented in Doherty et al. (2010). Several samples were collected from each location.

The snow densities (weight per volume) were measured manually, for either the whole snowpack vertical column (snow tube for SR and SNORTEX data), or for separate horizontal snow layers (density cutter for SoS data to measure the density of the visually dirty surface snow). One density measurement for each location was made. To estimate the stan-

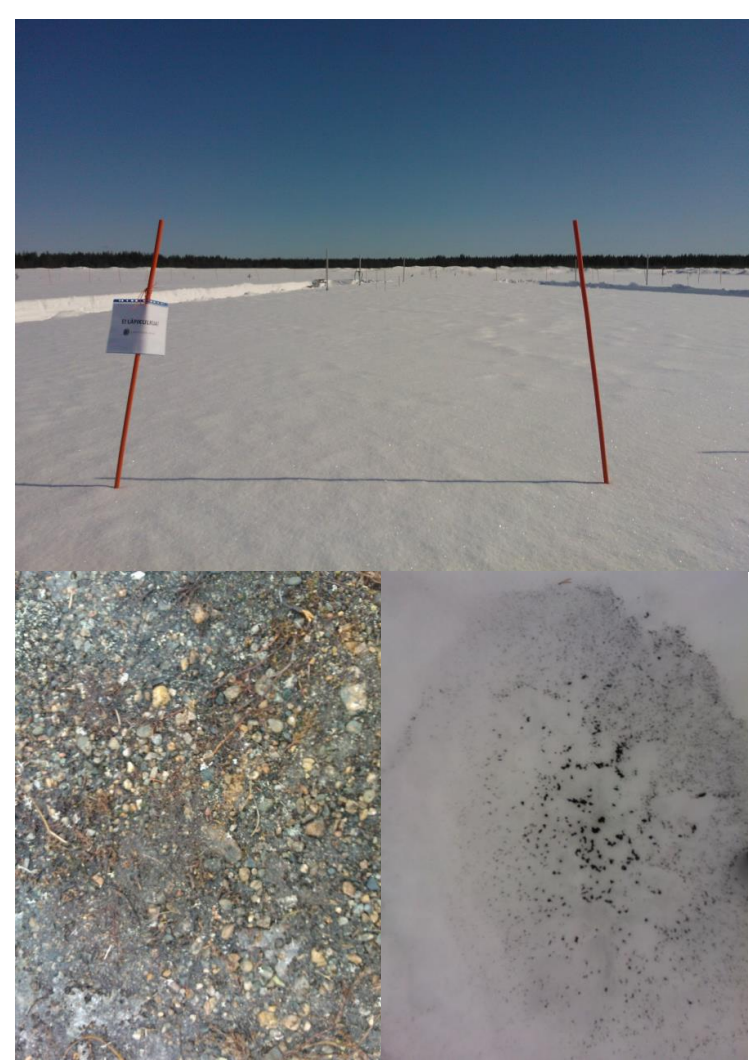

Figure 1. The SoS-2013 experiment. (a) Top: the flat and open experimental field with the seasonal snow pack; (b) bottom left: the ground under the snow, i.e. a natural gravel surface, not covered by concrete or asphalt, offered an uniform surface for the snow cover; (c) bottom right: previously added impurities were visible on the surface of the melting snow, here volcanic sand.

dard deviation of the density measurement, an earlier data set of FMI was applied. Sampling of wet snow for density measurements may be difficult since liquid water easily escapes from the sampling box. Here the SoS data for melting snow was obtained for two subsequent days (Table 1), before and after rainfall. The snow was then wet, but not dripping wet, and no water escape from sampling was detected.

In the SoS-2013 data, snow hardness, grain sizes, and grain shapes were estimated and classified according to the International Classification for Seasonal Snow on the Ground (Fierz et al., 2009).

\section{Results}

In our data for non-melting natural snow from the SR2009, SNORTEX-2009, SNORTEX-2010 and SoS-2013 campaigns, the BC concentrations varied between 8 and $126 \mathrm{ppb}$, and snow densities were $200-264 \mathrm{~kg} \mathrm{~m}^{-3}$. The density did not depend on the BC content (Fig. 2a, the dots inside the circle). 
Table 1. The origin of our Sodankylä snow density data coupled with BC analysis results. The campaigns are explained in the text.

\begin{tabular}{|c|c|c|c|c|c|c|}
\hline Year & Date & $\begin{array}{l}\text { Data } \\
\text { origin }\end{array}$ & Location & Snow & $\begin{array}{l}\text { Artificial } \\
\text { impurities }\end{array}$ & $\begin{array}{l}\mathrm{BC} \\
\text { analysis }\end{array}$ \\
\hline 2009 & 17 Mar & SR campaign & $\begin{array}{l}\text { Snow on lake } \\
\text { Orajärvi }\end{array}$ & Cold snow & No & Thermal-optical \\
\hline 2009 & 13, 19 Mar & SNORTEX & Sodankylä area & Cold snow & No & Thermal-optical \\
\hline 2010 & 23, $24 \mathrm{Mar}$ & SNORTEX & Sodankylä area & Cold snow & No & $\begin{array}{l}\text { Spectrometer } \\
\text { (Doherty et al., 2010) }\end{array}$ \\
\hline 2013 & $6,10 \mathrm{Apr}$ & SoS-2013 & Sodankylä airport & Cold snow & Yes & Thermal-optical \\
\hline 2013 & 17 Apr & SoS-2013 & Sodankylä airport & Melting, before rain & Yes & Thermal-optical \\
\hline 2013 & $18 \mathrm{Apr}$ & SoS-2013 & Sodankylä airport & Melting, after rain & Yes & Thermal-optical \\
\hline
\end{tabular}

However, in our SoS-experiment data of 6 April 2013, the snow with the BC maximum of 1465 ppb (Fig. 2a, one data point for wood burning soot), had the lowest density of all our data, $168 \mathrm{~kg} \mathrm{~m}^{-3}$. MFcr-grains (melt-freeze crust, as a result of melting and freezing) were $0.25-1.5 \mathrm{~mm}$ in diameter, the surface hardness value was 4 (hard snow) and the snow depth was $56 \mathrm{~cm}$. For comparison, with the reference nonsooted natural snow at that time (10 April 2013) on the same experimental field: the Ppir-grains (Precipitation particles) were irregular crystals, of $0.25-0.75 \mathrm{~mm}$ in diameter. The BC concentration was $126 \mathrm{ppb}$, the density was $210 \mathrm{~kg} \mathrm{~m}^{-3}$, the hardness value was 1 (very soft snow), and the snow depth was $65 \mathrm{~cm}$.

Our experimental data show that for the seasonally melting natural Arctic snow, with and without artificially added soot or volcanic ash, there was a correlation between the density and the BC content of snow (Fig. 2b). This was the case both prior to a rain period, and the next day after the rain. The densities and the corresponding $\mathrm{BC}$ contents were measured separately for the top $5 \mathrm{~cm}$ of the snow, not for the whole snow pack, and the impurities of volcanic sand, soot from oil burner and wood burning soot were visually observed to remain on the snow surface, too (Fig. 1). All the grains of the surface layer were melt-freeze crust (MFcr).

The BC concentrations in individual snow samples varied from 9 to $730 \mathrm{ppb}$. From these, the averages for each experimental spot were calculated (92-310 ppb), and plotted in Fig. 2b. The standard deviation $(\sigma)$ for the clean reference snow samples (no added impurities) was $34 \mathrm{ppb}(n=7)$, and most often $\sigma$ was larger for spots with added impurities, dependent on the number of samples (from 1 to 5) and the spot properties; e.g. for one spot with added soot, it was $\sigma=28 \mathrm{ppb}(n=5)$. The Eq. (1) shows the relation between the snow density $\rho_{\mathrm{s}}\left[\mathrm{kg} \mathrm{m}^{-3}\right]$, and the BC content $C_{\mathrm{BC}}$ [ppb] for the melting snow derived from the SoS-2013 data $\left(R^{2}=0.66\right)$ :

$\rho_{\mathrm{s}}=-0.27 C_{\mathrm{BC}}+440.6$,

where $C_{\mathrm{BC}}=[92,310] \mathrm{ppb}$. The $95 \%$ confidence interval of the slope of the Eq. (1) is from -0.46 to -0.08 , that is, we are $95 \%$ confident that the true slope of this equation is in the range defined by $-0.27 \pm 0.19$.

For the snow density, we had one measurement for each location. Therefore, using a previous FMI Sodankylä snow density data set (unpublished data), the average standard deviation was determined, providing a value of $17 \mathrm{~kg} \mathrm{~m}^{-3}$ ( $n=79$ pairwise measurements, $n_{\text {tot }}=158$, $\left.\rho_{\mathrm{s}}=[104,408] \mathrm{kg} \mathrm{m}^{-3}\right)$ for the Sodankylä data.

\section{Discussion and conclusions}

All our data of cold snow and melting snow represent the natural seasonal snow cover in Sodankylä, north of the Arctic Circle. For the cold snow, the density was $200-264 \mathrm{~kg} \mathrm{~m}^{-3}$ with BC 8-126 ppb. Our experimental results for an excessive (1465 ppb) amount of added BC (wood-burning soot) show a reduction of the cold snow density. This result is based on comparison of one sooted vs. one reference spot only; more data are needed to confirm this result. Earlier, Meinander et al. (2013) reported on a larger data set (their Table 3), where the snow BC content, in Sodankylä snow cover in 2009-2011, varied in one sampling location between 9 and $106 \mathrm{ppb}$ in the natural snow cover. Thus, our cold snow data presented here represents well the natural BC variability in Sodankylä.

Artificially added impurities in our experiments on natural snow decreased the snow density of melting snow (Fig. 2, Eq. 1). Moreover, the densities were measured both prior to and after rainfall $(4.9 \mathrm{~mm}$ water in $3 \mathrm{~h}$ ), which occurred between two subsequent measurement days. In both cases, the larger the BC content, the smaller the density. Thus the rain did not change this order, which further supported our hypothesis that the impurities may affect the water retention capacity. Furthermore, according to our recent laboratory experiment (unpublished data), we found that snow with artificially added soot released melt water sooner than snow without added soot. For this experiment, we added a known amount of soot to a snow sample, mixed the soot and snow, and let the snow melt indoors, while measuring the melt water on a drip pan as a function of time. The results showed 
(a)

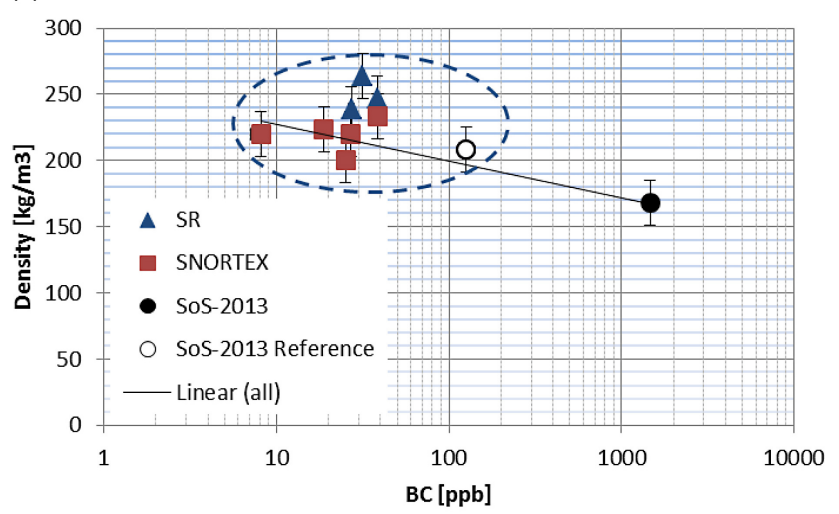

(b)

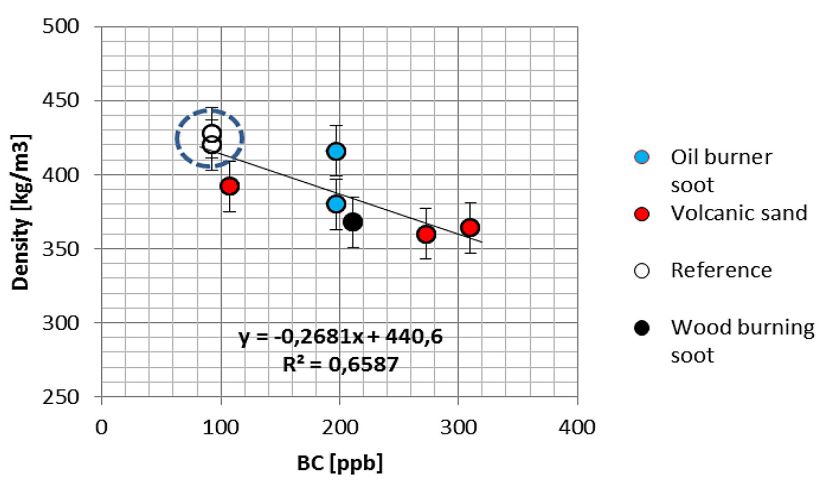

Figure 2. The black carbon (BC) content $[\mathrm{ppb}]$ vs. density $\left[\mathrm{kg} \mathrm{m}^{-3}\right]$ for the natural seasonal snow cover in Sodankylä, north of the Arctic Circle with and without artificially added impurities. The line is the least squares linear fit through all the points. (a) Cold snowpack: for natural snow without added impurities, BC concentrations were 8-126 ppb, and snow densities were $200-264 \mathrm{~kg} \mathrm{~m}^{-3}$ and for the reference SoS-2013 spot BC was $126 \mathrm{ppb}$ and the snow density was $210 \mathrm{~kg} \mathrm{~m}^{-3}$ (within the circle); when wood-burning soot was artificially deposited to this SoS-spot, BC in snow was measured to be $1465 \mathrm{ppb}$, and snow density decreased to $168 \mathrm{~kg} \mathrm{~m}^{-3}$ (outside the circle). (b) Melting snow: SoS-2013 data for reference spots (within the circle), and spots with artificially added impurities of volcanic sand, soot from oil burner and wood burning soot (outside the circle). The densities and corresponding carbon contents were measured separately for the specified surface layers, not for the entire snow pack.

that while the control snow started to release melt water after $40 \mathrm{~min}$, the snow with added soot released melt water already after $12 \mathrm{~min}$. When cold water was added on snow, the control snow released water after $29 \mathrm{~min}$, while the same amount of water in sooted snow caused water to release already after $7 \mathrm{~min}$. All the snow samples were of the same size (same weight and volume) representing the same natural snow, and mechanically treated the same way whether soot was added or not, for example, the control snow was also mixed although no soot was added. Hence, these new experimental data were found to support our hypothesis that BC may decrease the liquid-water retention capacity of melting snow.

As a summary, according to our experience and observations, we suggest three possible processes that might lead to the lower snow density:

1. A semi-direct effect of absorbing impurities. Absorbing impurities would cause melt and/or evaporation from the liquid phase and sublimation from the solid phase of the surrounding snow, resulting in air pockets around the impurities, and thus lower snow density. We have empirical observations, where impurities (both organic and inorganic) in the snow have been surrounded by air pockets.

2. BC effect on the adhesion between liquid water and snow grains. If BC reduces adhesion, the liquid-water holding capacity decreases. For linear warming the influence on the density of wet snow is then max $5 \%$ (at this level water flow starts in natural snow). However, with daily cycles, warm days and cold nights, the weaker adhesion may push liquid water down more dayby-day and then the influence to the density would be larger. This way also melt-freeze metamorphosis would produce less dense snow.

3. BC effect on the snow grain size. Absorbing impurities would increase the melting and metamorphosis processes, resulting in larger snow grains, which would lower the water retention capacity. Earlier, Yamaguchi et al. (2010) have suggested that the water retention curve of snow could be described as a function of grain size using soil physics models. Here our data showed some slight indication for the possibility of soot in snow to result in larger snow grain sizes via increased melt and metamorphosis, and our data did not show clear evidence against this possibility.

Volcanic sand is assumed not to contain BC (Dadic et al., 2013, Fig. 12a). This assumption is further supported by our own EC analysis of volcanic sand samples with the thermal - optical method showing hardly any EC. Instead, the BC in our volcanic sand spot can be assumed to originate either from long-range transport, or from our other experimental spots with added soot; carbonaceous material in volcanic aerosols has also been proposed to be due to tropospheric air that is entrained into the volcanic jet and plume (Andersson et al., 2013). Our observations and measurements indicate that for a visually darker snow surface, the analyzed BC content is larger and the measured snow density is smaller, regardless of whether soot or volcanic sand had been added to the spot.

The significance of our results on reduction of snow density, and possibly also decreasing water holding capacity due to the black carbon, may be due to the fact that (i) snow density is an important snow parameter that has been found to 
correlate with several factors affecting the snow melt, such as snow age and liquid-water holding capacity (Kuusisto, 1984); (ii) snow density multiplied by snow depth equals the important climate model parameter of snow water equivalent (SWE); and (iii) our results may have potential in reducing the uncertainties (IPCC, 2013) related to the effect of black carbon on snow melt and climate change.

In nature, the low density of new dry snow increases due to gravitational settling, wind packing, sintering, and meltfreeze events. These processes depend on the grain size, shape and organization, and snow temperature. The density of snow is also affected by water vapour diffusion in the snow pack, as well as by the temperature and the vegetation under the snow. In our experimental data, we can assume similar environmental conditions with only the impurity contents in snow being the varying factor; our results are for natural snow on natural ground, and we did not have data for drainage of melt water in the snowpack. Here we reported our first results, and more data are needed to further study the effect of light-absorbing impurities on density and water retention capacity of melting snow.

Acknowledgements. The authors thank all the participants of the campaigns of SoS-2013, SNORTEX-2010, SNORTEX-2009 and SR-2009, especially Antti Aarva. Filters from the 2010 snow samples were analyzed for BC by S. Doherty. We gratefully acknowledge support from the Academy of Finland (A4-project), and the Nordic Center of Excellence (NCoE), Nordic Top Research Initiative "Cryosphere-atmosphere interactions in a changing Arctic climate" (CRAICC), and the EU Life+ project Mitigation of Arctic warming by controlling European black carbon emissions, MACEB (project no. LIFE09 ENV/FI/000572).

Edited by: M. Boy

\section{References}

Andersson, S. M., Martinsson, B. G., Friberg, J., Brenninkmeijer, C. A. M., Rauthe-Schöch, A., Hermann, M., van Velthoven, P. F. J., and Zahn, A.: Composition and evolution of volcanic aerosol from eruptions of Kasatochi, Sarychev and Eyjafjallajökull in 2008-2010 based on CARIBIC observations, Atmos. Chem. Phys., 13, 1781-1796, doi:10.5194/acp-13-1781-2013, 2013.

Bond, T. C., Doherty, S. J., Fahey, D. W., Forster, P. M., Berntsen, T., DeAngelo, B. J., Flanner, M. G., Ghan, S., Kärcher, B., Koch, D., Kinne, S., Kondo, Y., Quinn, P. K., Sarofim, M. C., Schultz, M. G., Schulz, M., Venkataraman, C., Zhang, H., Zhang, S., Bellouin, N., Guttikunda, S. K., Hopke, P. K., Jacobson, M. Z., Kaiser, J. W., Klimont, Z., Lohmann, U., Schwarz, J. P., Shindell, D., Storelvmo, T., Warren, S. G. and Zender, C. S.: Bounding the role of black carbon in the climate system: A scientific assessment, J. Geophys. Res.-Atmos., 118, 5380-5552, doi:10.1002/jgrd.50171, 2013.
Conway, H., Gades, A., and Raymond, C. F.: Albedo of dirty snow during conditions of melt, Water Resour. Res., 32, 1713-1718, 1996.

Dadic, R., Mullen, P. C., Schneebeli, M., Brandt, R. E., and Warren, S. G.: Effects of bubbles, cracks, and volcanic tephra on the spectral albedo of bare ice near the Transantarctic Mountains: Implications for sea glaciers on Snowball Earth, J. Geophys. Res.Earth, 118, 1658-1676, doi:10.1002/jgrf.20098, 2013.

DeWalle, D. R. and Rango, A.: Principles of snow hydrology, Cambridge University Press, Cambridge, UK, 2008.

Doherty, S. J., Warren, S. G., Grenfell, T. C., Clarke, A. D., and Brandt, R. E.: Light-absorbing impurities in Arctic snow, Atmos. Chem. Phys., 10, 11647-11680, doi:10.5194/acp-1011647-2010, 2010.

Doherty, S. J., Grenfell, T. C., Forsström,S., Hegg, D. L., Brandt, R. E., and Warren, S. G.: Observed vertical redistribution of black carbon and other insoluble light-absorbing particles in melting snow, J. Geophys. Res.-Atmos., 118, 5553-5569, 2013.

Fierz, C., Armstrong, R. L., Durand, Y., Etchevers, P., Greene, E., McClung, D. M., Nishimura, K., Satyawali, P. K. and Sokratov, S. A.: The International Classification for Seasonal Snow on the Ground, IHP-VII Technical Documents in Hydrology No. 83, IACS Contribution No. 1, UNESCO-IHP, Paris, 2009.

Forsström, S., Ström, J., Pedersen C. A., Isaksson, E., and Gerland, S.: Elemental carbon distribution in Svalbard snow, J. Geophys. Res., 114, D19112, doi:10.1029/2008JD011480, 2009.

IPCC, "Climate Change 2013: The Physical Science Basis. Working Group I Contribution to the IPCC 5th Assessment Report - Changes to the Underlying Scientific/Technical Assessment" (IPCC-XXVI/Doc.4), http://www.ipcc.ch/report/ar5/wg1/ (last access: 22 May 2014), 2013.

Kuusisto, E.: Snow accumulation and snowmelt in Finland. Publications of the Water Research Institute, National Board of Waters, Finland, No. 55, 149 pp., 1984.

Meinander, O., Kazadzis, S., Arola, A., Riihelä, A., Räisänen, P., Kivi, R., Kontu, A., Kouznetsov, R., Sofiev, M., Svensson, J., Suokanerva, H., Aaltonen, V., Manninen, T., Roujean, J.-L., and Hautecoeur, O.: Spectral albedo of seasonal snow during intensive melt period at Sodankylä, beyond the Arctic Circle, Atmos. Chem. Phys., 13, 3793-3810, doi:10.5194/acp-13-37932013, 2013.

Warren, S. G. and Wiscombe, W. J.: A model for the spectral albedo of snow. II: Snow containing atmospheric aerosols, J. Atmos. Sci., 37, 2734-2745, 1980.

Yamaguchi, S. Katsushima, T., Sato, A., and Kumakura, T.: Water retention curve of snow with different grain sizes, Cold Reg. Sci. Technol., 64, 87-93, doi:10.1016/j.coldregions.2010.05.008, 2010. 